\title{
Dual Roles of Fer Kinase Are Required for Proper Hematopoiesis and Vascular Endothelium Organization during Zebrafish Development
}

\author{
Emily M. Dunn ${ }^{1}$, Elizabeth J. Billquist ${ }^{2}$, Amy L. VanderStoep ${ }^{2}$, Phillip G. Bax ${ }^{1}$, \\ Laura M. Westrate ${ }^{3}$, Lisa K. McLellan ${ }^{2}$, Shelby C. Peterson ${ }^{2}$, Jeffrey P. MacKeigan ${ }^{3}$ \\ and Aaron P. Putzke ${ }^{1, *}$ \\ 1 Department of Biology, Whitworth University, Spokane, WA 99251, USA; \\ edunn@whitworth.edu (E.M.D.); pbax18@my.whitworth.edu (P.G.B.) \\ 2 Department of Biology, Hope College, Holland, MI 49423, USA; ebillquist@luc.edu (E.J.B.); \\ vande867@msu.edu (A.L.V.); lmclellan@wustl.edu (L.K.M.); scpete@umich.edu (S.C.P.) \\ 3 Center for Cancer Cell Biology, Van Andel Research Institute, Grand Rapids, MI 49503, USA; \\ laura.westrate@colorado.edu (L.M.W.); jeff.mackeigan@vai.org (J.P.M.) \\ * Correspondence: aputzke@whitworth.edu; Tel.: +1-509-777-4822
}

Academic Editor: Chris O'Callaghan

Received: 15 October 2017; Accepted: 18 November 2017; Published: 23 November 2017

\begin{abstract}
Fer kinase, a protein involved in the regulation of cell-cell adhesion and proliferation, has been shown to be required during invertebrate development and has been implicated in leukemia, gastric cancer, and liver cancer. However, in vivo roles for Fer during vertebrate development have remained elusive. In this study, we bridge the gap between the invertebrate and vertebrate realms by showing that Fer kinase is required during zebrafish embryogenesis for normal hematopoiesis and vascular organization with distinct kinase dependent and independent functions. In situ hybridization, quantitative PCR and fluorescence activated cell sorting (FACS) analyses revealed an increase in both erythrocyte numbers and gene expression patterns as well as a decrease in the organization of vasculature endothelial cells. Furthermore, rescue experiments have shown that the regulation of hematopoietic proliferation is dependent on Fer kinase activity, while vascular organizing events only require Fer in a kinase-independent manner. Our data suggest a model in which separate kinase dependent and independent functions of Fer act in conjunction with Notch activity in a divergent manner for hematopoietic determination and vascular tissue organization.
\end{abstract}

Keywords: non-receptor tyrosine kinase; erythrocyte; vasculature; embryogenesis

\section{Introduction}

The formation of germ layers during vertebrate development leads to increasing levels of molecular fine tuning that result in the differentiation of specific tissue types. Proper differentiation relies heavily on transcriptional regulation and cellular adhesion, both of which are mediated by different types of kinase signaling. Kinase signaling during development has been well characterized and involves myriad kinases, including both receptor and non-receptor tyrosine kinases, such as the well-known Src family kinases (reviewed in [1-3]). Additionally, the emergence of the dualistic properties of some kinases has revealed novel avenues of protein functions which will further clarify complex signaling roles in cellular regulation.

One subset of non-receptor tyrosine kinases (NRTKs) is the Fes/Fps family that includes the Fer (Fes-Related) kinase. Fer kinase expression was first detected in both human and mouse (leukemic and erythroblast) cells [4], and has been shown to be highly conserved throughout evolution $[5,6]$. 
Fer kinase contains an N-terminal F-BAR domain, shown to be involved in stabilizing interactions with cytoskeletal elements that recruit Fer to the plasma membrane, a Src homology 2 (SH2) domain and a tyrosine kinase (TyrKin) domain [7]. Additionally, Fer also has a coiled-coil domain that facilitates homotypic oligomerization and autophosphorylation by forming homotrimers, which are not required for kinase activity [8]. Fer has been shown to be activated via pathways, such as epidermal growth factor receptor (EGFR) and platelet derived growth factor (PDGF), and phosphorylate protein targets, such as Stat3 [9-14]. However, the required in vivo functions of Fer during development remain largely unknown.

Fer kinase is conserved across invertebrate and vertebrate phyla. For example, Fer expression has been detected in sea sponges [15], nematodes [16], fruit flies [17,18], rats and humans [6]. In vertebrates, two versions of Fer have been observed in mice and humans, the full length version, found ubiquitously expressed, and a testis specific version, arising from an internal start site [6,19]. Interestingly, there is greater variability among invertebrates regarding different versions of Fer, such that while fruit flies have been shown to express both versions [18]; nematodes only express the truncated, but not the full length, version of Fer [16]. Recently, the full length version of Fer has been shown to be expressed during zebrafish development in a ubiquitous manner early, while later concentrating to the head region and fin buds [20]. In addition, the same study reported developmental defects ranging from convergent extension to craniofacial defects when knocking down Fer using morpholino technology [20].

Fer kinase has been linked to a variety of cellular functions, such as cytoskeletal interactions, mediating cadherin and integrin dependent adhesion that can lead to cellular migration [21-23]. Interestingly, the absence of Fer kinase has been shown to lead to developmental defects during embryonic enclosure in nematodes [16] and fruit flies [24], both of which are cadherin dependent adhesion functions of Fer. Fer kinase has also been shown to be involved in cellular proliferation under normal conditions in human and worms [25-27]. Importantly, Fer kinase has been reported to regulate cancer progression where it appears to be functioning in a finely tuned balance, such that when either over-expressed in renal cell carcinomas [28,29] or deleted in myeloid leukemia [30] or lung cancer [31], the cellular functions of Fer are perturbed and result in similar negative consequences (such as loss of cadherin-complex stability). Furthermore, an RNA interference screen effectively demonstrated that Fer kinase plays a significant role in cancer cell survival, and also that the loss of Fer enhanced cell death in conjunction with chemotherapeutic agents [32].

More recently, kinase inactive protein functions have been reported, showing that there are critical aspects of kinases that do not require their phosphorylation capacity to be intact (reviewed in [3]). Kinase independent roles for Fer have been demonstrated, due to the sustained viability and fertility of mice expressing a kinase inactive version of Fer [12], as well as the ability of a similar kinase inactivating mutations in Fer to rescue embryonic development in nematodes [16]. Interestingly, both Fer and Fes/Fps have been reported to be redundant in regulating hematopoiesis [33]. Parsing out the functions of Fer that are independent of kinase activity will shed more light on the complexities of the signaling pathways involved, and may allow for more clarification on overlapping roles within the Fes-Fps subfamily of NRTKs.

In this study, we characterized a novel expression pattern and functional component to Fer during zebrafish embryonic development, which has not previously reported. We report here that not only is Fer required for proper axis determination and formation of head structures during embryogenesis (as reported by [20], but also for proper organization of the vascular endothelium and hematopoietic proliferation in the trunk region. The absence of Fer results in disorganized trunk vasculature within the region of the cardinal vein (CV), dorsal aorta (DA) and intersegmental vessels (ISV), resulting in subsequent loss of erythrocyte circulation. Additionally, we observed an increase in hematopoietic cell markers in the region of the intermediate cell mass (ICM), corresponding to an increase in the number of erythrocytes. Finally, we demonstrated diverging roles for Fer, with Fer kinase activity required for 
the proper proliferation of hematopoietic cell populations, but a kinase independent role in proper organization of the vascular endothelium via the Notch pathway.

\section{Materials and Methods}

\subsection{Transgenic Zebrafish Lines}

Wildtype (AB) zebrafish as well as lines expressing either fli1a::nEGFP (y7Tg) or gata1a::dsRed $(s d 2 \mathrm{Tg}$ ) were obtained from the Zebrafish International Resource Center (Eugene, OR, USA), from which we generated a stable fli1a::nEGFP (y7Tg), gata1a::dsRed (sd2Tg) double transgenic line. All lines were maintained according to standard zebrafish husbandry protocols, as previously described [34].

\subsection{Fer Morpholino Knockdown}

Antisense morpholino oligonucleotides (MOs) were generated by Gene Tools, LLC (Philomath, OR, USA). fer-MO1 (5'-CTGGAAGAGAGACAGAGATCACACT- $3^{\prime}$ ) was designed against the splice acceptor site in intron 8 of fer in order to prevent proper splicing with exon 9 , thus facilitating an exon-8-10 splice, generating a premature stop codon in the translated product. The control morpholino was a 25-mer of randomized nucleotides purchased from Gene Tools, LLC. The oligonucleotides were solubilized in RNase-free water at a concentration of $1 \mathrm{mM}$ and stored according to the manufacturer's instructions. The injections were made by diluting the oligonucleotides with phenol red and RNase-free water. Titration of the morpholino was achieved by injecting $1 \mathrm{~nL}$ at concentrations from $0.25 \mathrm{mM}(2 \mathrm{ng} / \mathrm{nL})$ to $0.5 \mathrm{mM}(4 \mathrm{ng} / \mathrm{nL})$ to determine the optimum level for microinjection (which was $0.5 \mathrm{mM}$ ). An exception to this is the MO concentration used in the tubulogenesis/circulation experiments with Rhodamine-Dextran was $0.25 \mathrm{mM}$. The Fer rescue experiments were performed by injecting $1 \mathrm{~nL}$ of $0.5 \mathrm{mM}$ fer-MO1 and control MO. Improper splicing with the fer $\mathrm{MO}$ was confirmed using PCR to amplify the region spanning exon 9, using a forward primer in exon 8 ( $5^{\prime}$-AGTCCACCACAGAGGAGCTG-3') and a reverse primer in exon 10 (5'-AGTCTGTCCTTGGCTCTTCG-3') (Figure 2I). Although not shown here, experiments repeated with MOs and PCR primers, as reported by Paardekooper Overman, et al. (P-O MO), confirmed specificities for the Fer gene were consistent with data obtained using our fer-MO1 (Fer protein knockdown with both MOs is shown in Supplementary Figure S1 as fer-MO1 and P-O MO) [20]. Morpholino knockdown was confirmed using a Western blot analysis, using an anti-Fer monoclonal antibody (Cell Signaling).

\subsection{Whole Mount In Situ Hybridization (WISH)}

Embryos were collected and fixed in $4 \%$ PFA overnight at $4{ }^{\circ} \mathrm{C}$ before performing WISH, as previously described [35]. Probes for fer, fli1, gata1, scl, c-myb, hbbe2, and runx1 were generated from linearized plasmid containing the cDNA of interest, using either T7 or SP6 RNA polymerase (Ambion) and digoxygenin-UTP labeling mix (Roche). The embryos were washed in a series of glycerol/PBS solutions, where the percent glycerol was increased from 30 to 70 percent, prior to mounting on slides and imaging.

\section{4. o-Dianisidine Staining}

Control and fer-MO1 embryos were collected and dechorionated at the desired developmental stages. They were then immediately stained for approximately $30 \mathrm{~min}$ in a fresh solution of $0.6 \mathrm{mg} / \mathrm{mL}$ o-dianisidine, $0.01 \mathrm{M}$ sodium acetate ( $\mathrm{pH} 4.5), 0.65 \% \mathrm{H}_{2} \mathrm{O}_{2}$, and $40 \%$ ethanol. After staining, they were cleared with a solution of 2:1 benzyl benzoate/benzyl alcohol.

\subsection{Microangiography}

At $48 \mathrm{~h}$ post-fertilization (hpf), fer-MO1 and control embryos (using the fli1a::nEGFP transgenic line) were anesthetized and mounted in low-melting agarose. They were then injected in the dorsal aorta (trunk region at the posterior end of the yolk extension) or the sinus venosus with $1 \mathrm{~nL}$ of a 
$12 \mathrm{nM}$ solution of red fluorescent Rhodamine-Dextran beads (70,000 MW, Molecular Probes, Eugene, OR, USA) and given 15-20 min for the beads to circulate prior to imaging.

\subsection{Quantitative PCR ( $q P C R)$}

Using a QIAGEN RNeasy kit, the total RNA of control and fer-MO1 injected embryos was isolated at the indicated time points and then reverse transcribed to cDNA using a FirstChoice RLM RACE kit (Ambion), which was used in all subsequent PCR reactions. Primer pairs for $k d r l / f l k 1$, fli1, gata1, scl, runx1, notch1b, c-myb, hbbe2 and fer were designed using Primer3 and chosen to have fragment size between 150 and 200 base pairs (Supplemental Table S1). qPCR was performed using a SsoFast EvaGreen Supermix (BioRad) and a C1000 thermocycler with the CFX96 Real Time System (BioRad). Experiments were repeated twice, with gene targets analyzed in triplicate with each run. A melt curve was used to confirm the purity of the analyzed product. The analysis was performed by normalizing the target genes to actin.

\subsection{Fluorescence Activated Cell Sorting (FACS)}

Zebrafish embryos that were injected with fer-MO1 or control MO were collected at $28 \mathrm{hpf}$ and subjected to cell dissociation and resuspended in PBS, as previously described [36]. Cells were sorted on a BD FACS Caliber flow cytometer (BD Biosciences, San Jose, CA, USA) using FL3 to determine gata1::dsRed fluorescence, and FL1 to determine fli1a::nEGFP fluorescence. Cells were gated by $n E G F P$ or $d s R e d$ signal using CellQuest Pro to determine the number of gata1 and fli1a expressing cells in each sample. At least 10,000 cells were counted per treatment and the experiment was repeated twice, with error determined via calculation of the standard deviation.

\subsection{Fer Kinase Inactivating Point Mutations and Notch Rescue Experiments}

Point mutations in fer were generated separately in the $\mathrm{SH} 2$ and tyrosine kinase domains of the zebrafish Fer with a cloned full length cDNA (clone ID:7060149 from Open Biosystems-Dharmacon, Lafayette, CO, USA) using the QuikChange Lightning Site-Directed Mutagenesis kit (Agilent) and the sequence confirmed (Figure 7O). The plasmids were linearized with NotI and capped mRNA (including point mutants, wildtype and anti-sense) was made using the SP6 mMessage mMachine kit (Ambion). Approximately $25 \mathrm{pg}$ of mRNA was co-injected with $0.25 \mathrm{mM} \mathrm{MO}$ (fer-MO1 or control MO). The zebrafish Notch Intracellular Domain (NICD) construct was obtained (Addgene, Cambridge, MA, USA, 453 pCSMTN5ICD was a gift from Nathan Lawson, plasmid \# 22466)) and capped mRNA made using the SP6 mMessage mMachine kit. NICD expression was confirmed by Western blot analysis, using an anti-activated Notch antibody (AbCam).

\subsection{Imaging}

All imaging was performed on either a Nikon SMZ1500 dissecting microscope, an inverted, epifluorescent Zeiss Apotome microscope or a laser scanning confocal microscope (Nikon A1R and Leica SPE). (Nikon, Tokyo, Japan) (Zeiss, Oberkochen, Germany) (Leica, Wetzlar, Germany).

Three dimensional (3D) reconstructions were obtained by mounting embryos at $28 \mathrm{hpf}$ in low melting agarose and these were imaged following stimulation with the $488 \mathrm{~nm}$ and $561 \mathrm{~nm}$ diode lasers, using a Plan Apo $\lambda$ 20x objective. Mounted embryos were placed on the stage of the Nikon A1 microscope within an Okolab stage-top incubation system that maintained a temperately controlled environment of $28.5^{\circ} \mathrm{C}$. A NIS Elements (Nikon) device was used to visualize the zebrafish embryos and perform $3 \mathrm{D}$ reconstructions (from z-stacks). 


\section{Results}

\subsection{Fer Kinase Is Expressed during Embryogenesis}

Using the predicted amino acid sequence of the zebrafish Fer, we compared Fer homologues among a wide variety of organisms, ranging from invertebrates to vertebrates (Figure 1A). The resulting phylogenetic analysis showed that the zebrafish Fer is 74 percent homologous to the human Fer, being conserved throughout the F-Bar, FX, SH2 and tyrosine kinase domains, thus serving as an important "bridge" between the invertebrate and vertebrate versions of Fer. We generated gene specific probes to fer cDNA for in situ hybridization, to determine the spatio-temporal expression during development. Similar to what was reported by Paardekooper Overman et al. [20], we found fer to be expressed ubiquitously until approximately ten somites, when it became more specifically concentrated toward the head region. However, we also observed fer expression in the primordial region of the dorsal aorta (DA)/ cardinal vein (CV), when compared to a fer antisense probe negative control (In Figure 1B,C, respectively-24 hpf is shown). This expression pattern decreased in intensity until approximately 72 hpf, when fer expression was no longer detectable in the ICM region. Confirmation by quantitative PCR showed highest expression of fer early in development, which decreased until 24 hpf, when it appeared to stabilize at a level three to four-fold lower than the earliest expression (Figure 1D).

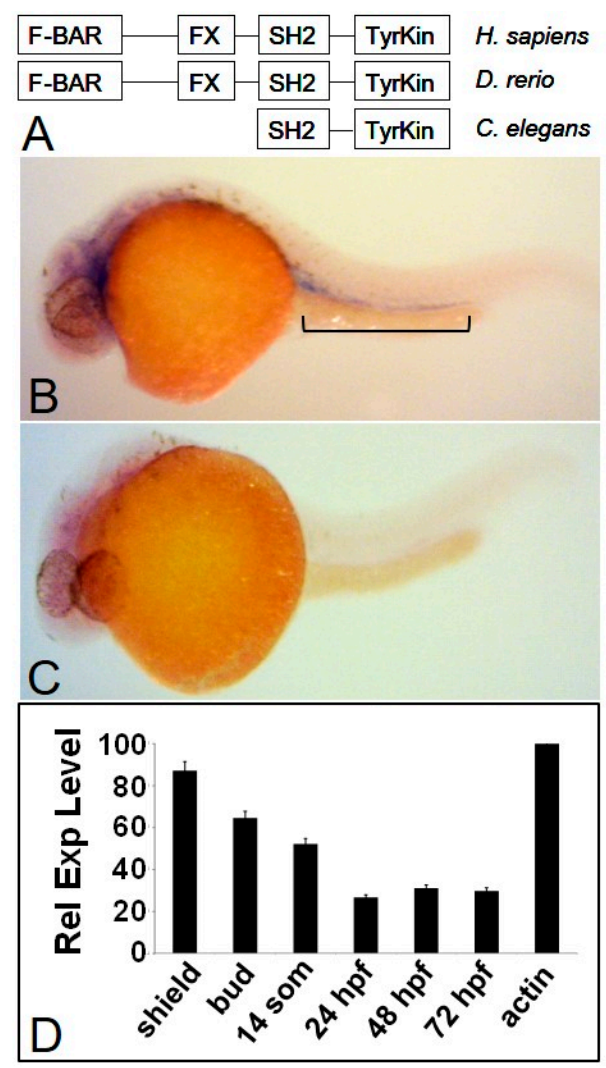

Figure 1. Fer kinase is conserved throughout evolution and is expressed during zebrafish embryogenesis. The zebrafish homologue of Fer kinase is highly conserved throughout eukaryotic organisms and contains the same domains as the human version (A). The zebrafish homologue of the fer kinase gene is expressed ubiquitously during early developmental stages with more specific expression emerging between 24 and $72 \mathrm{hpf}$ (not shown). At $24 \mathrm{hpf}$, fer expression is observed in the intermediate cell mass (ICM) and developing brain region (B), when compared to a fer anti-sense probe (C). Quantitative PCR shows fer expression is highest during early development and tapers off by $24 \mathrm{hpf}$ to three to four-fold lower levels (D). 


\subsection{Fer Kinase Is Required for Proper Blood and Vasculature Development in Zebrafish}

The requirement for the zebrafish Fer kinase homologue during development was examined using knockdown with gene specific morpholinos (see methods). In the absence of Fer kinase, we observed the arrest of embryonic development at $72 \mathrm{hpf}$, with severe defects in hematopoiesis, vasculogenesis, heart development and the central nervous system. In the absence of Fer kinase, at 30 somites ( $28 \mathrm{hpf})$ we observed a lack of circulating blood cells (Figure 2A, Supplemental Video S1) when compared to control MO injected embryos (Figure 2C, Supplemental Video S2); this was emphasized by the absence or pooling of hematopoietic cells in the region of the ICM. All embryos were imaged after reaching the same stage, which, in the absence of Fer kinase, resulted in a shortening of the anterior-posterior axis, similar to what was observed by Paardekooper Overman et al. [20]. In addition to the lack of circulating erythrocytes, the absence of Fer kinase activity led to general cardiac development defects, along with pericardial edema (Figure 2B,F, Supplemental Video S3) when compared to wildtypes (Figure 2D,H, Supplemental Video S4). In Fer deficient embryos, the heart chambers both contracted, although in the majority of embryos, the heart chamber contraction occurred erratically and asynchronously, when compared with wildtypes. In this study we therefore chose to focus our investigation on the hematopoietic and vascular defects.

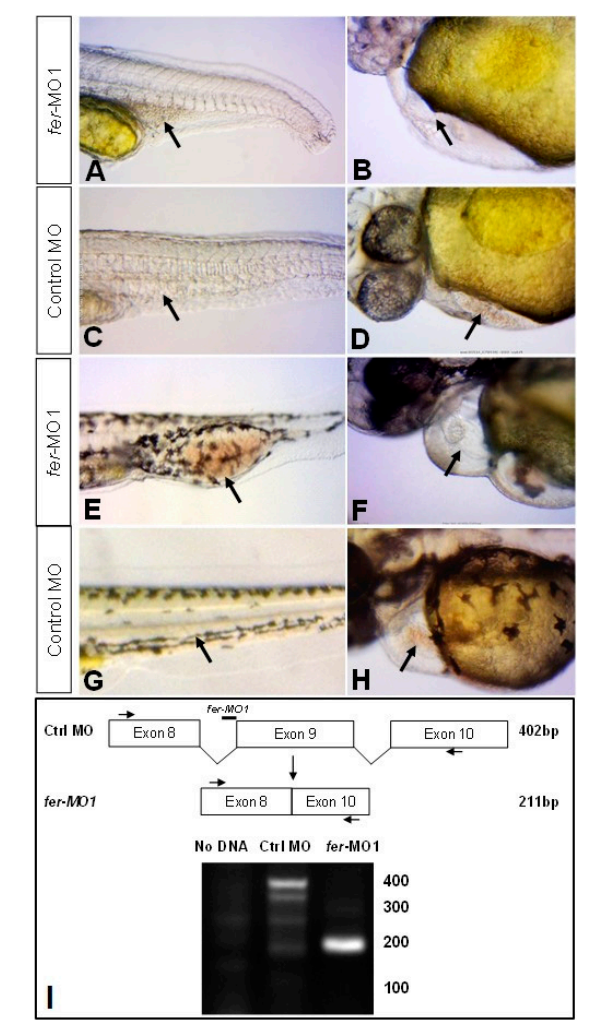

Figure 2. Fer knockdown results in apparent vasculature blockage and accumulation of developing hematopoietic cells. At 30 somites, fer-MO1 embryos exhibit convergence extension defects along the anterior-posterior axis with red blood cells that are pooled in the posterior ICM region (A) with none present in the pumping heart (B), when compared to wildtypes ((C,D) respectively). By $48 \mathrm{hpf}$, the lack of circulating red blood cells and empty heart chambers is emphasized in the Fer knockdown embryos (E,F) compared to wildtype embryos (G,H). Agarose gel electrophoresis of fer-reverse transcription PCR from fer-MO1 injected embryos to demonstrate the blockage of Fer splicing at exon 9 (I).

We found there were two categories of severity in the loss of circulation in fer-MO1 injected embryos, with 78.4 percent of embryos containing primarily non-circulating erythrocytes and 21.6 percent of embryos containing no visibly circulating erythrocytes $(n=223)$. A loss of circulating 
erythrocyte populations was observed in control MO injected embryos less than one percent of the time $(n=258)$. In the category containing non-circulating erythrocytes, the fer-MO1 phenotype became more pronounced by $48 \mathrm{hpf}$ (Figure 2E), with the group of non-circulating erythrocytes expanding in number in the region of the ICM, compared to the control $\mathrm{MO}$ embryos, where no non-circulating erythrocytes were observed (Figure 2G).

To confirm that the cells present were differentiated erythroid cells, we performed o-dianisidine staining, which labels erythrocyte populations expressing hemoglobin. The loss of Fer kinase resulted in decreased erythrocytes in the anterior region and visible pooling of cells in the posterior (ICM) region of the embryo at $28 \mathrm{hpf}$ (Figure 3A,C, control embryos Figure 3B,D, $n=25$ per condition). At 48 and $72 \mathrm{hpf}$, erythrocytes in the fer-MO1 embryos were present in the anterior region, due to the normal production of erythrocytes that occurs during this time from the aorta-gonad-mesonephros (AGM). However, in the most severe embryos (lacking Fer activity), there was still no detection of hemoglobin containing cells in the posterior trunk region during these time points (Figure 3E, G, $n=25$ per condition). In contrast, control MO injected embryos contained erythrocytes throughout their entire circulatory system (Figure 3F,H). Normally, by $48 \mathrm{hpf}$, erythrocytes are no longer produced in the region of the ICM, thus the lack of trunk staining of the fer-MO1 embryos at 48 and $72 \mathrm{hpf}$ suggests the absence of circulation rather than an inhibition of erythrocyte development at the later time points.

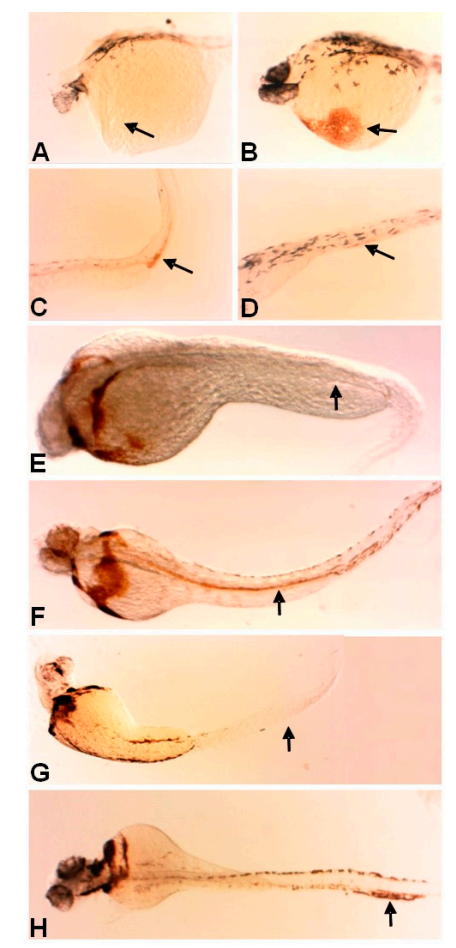

Figure 3. The loss of Fer kinase function resulted in the loss of early anterior erythrocyte formation and the loss of circulation. o-Dianisidine staining showed the slightly higher levels of erythrocyte heme groups in the posterior trunk region of fer-MO1 embryos at 30 somites ( $28 \mathrm{hpf}$ ) (C, control-D), but not in the anterior (A), as is observed in control embryos (B). The staining was no longer present in the posterior region at 48 and $72 \mathrm{hpf}$ in fer-MO1 ((E,G) respectively) but regained anterior staining, indicating that later erythrocyte production is functional but no circulation is taking place (control $\mathbf{F}$ and $\mathbf{H}, 48$ and $72 \mathrm{hpf}$ respectively).

To better visualize the defects in erythrocyte circulation in the absence of Fer kinase we generated a stable fli1a::nEGFP, gata-1::dsRed double transgenic line to observe both vascular and hematopoietic cells in the same embryos. Using this model, in the absence of Fer activity, we observed a lack of organization within the region forming the dorsal aorta and the cardinal vein, as well as a significant 
loss of ISV formation (i.e., decrease in the number of fli1a::nEGFP migrating cells) at both 30 somites ( $28 \mathrm{hpf})$ and $48 \mathrm{hpf}$ in 82.1 percent of the embryos $(n=56)$ (Figure $4 \mathrm{~A}, \mathrm{~B})$, when compared to the control embryos where no loss of vascular organization was observed in any embryos $(n=47)$ (Figure $4 \mathrm{E}, \mathrm{F}$ ). Additionally, we found that in embryos with disorganized vasculature, there was a corresponding abundance of gata1::dsRed expressing cells in the region of the ICM. However, these gata1::dsRed cells were completely stationary, with no observable movement into the ISVs (Figure 4C,D show punctate dots); which is in contrast to the control embryos, where cells could be observed moving within the dorsal aorta (Figure 4G,H—static images, lack of puncta in $\mathrm{H}$ indicates circulating cells).

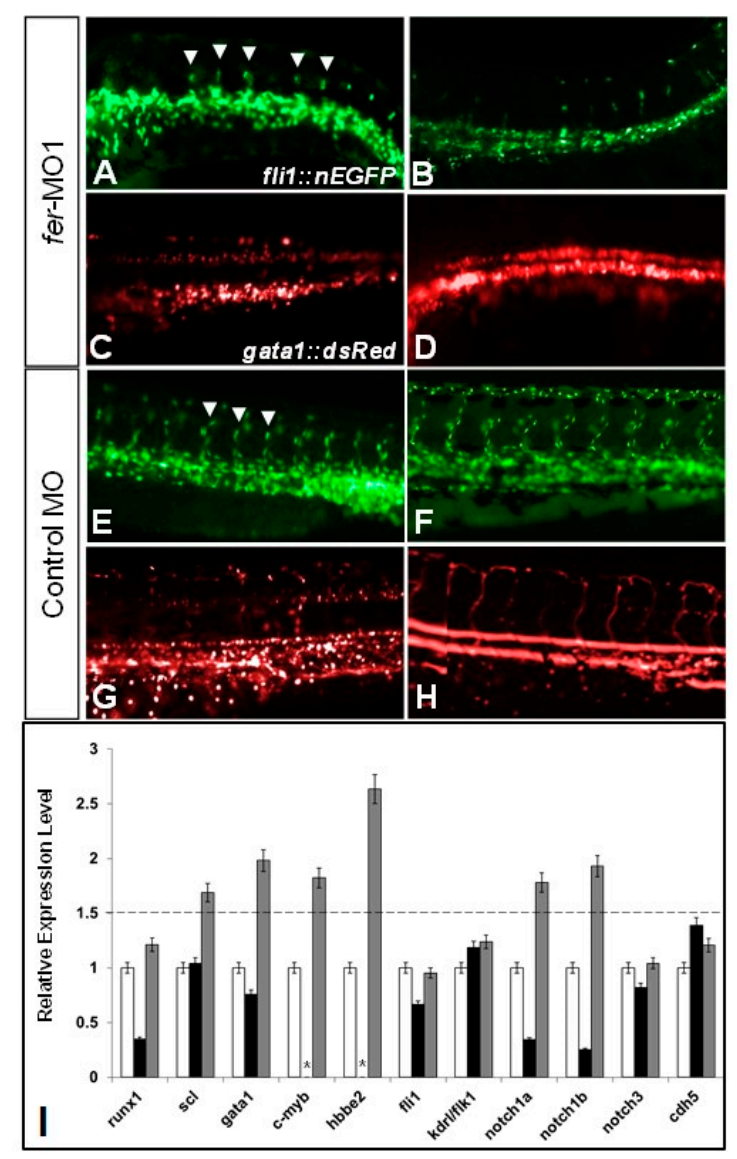

Figure 4. The loss of Fer kinase function resulted in intersegmental vessel (ISV) formation defects and loss of blood flow in zebrafish embryos. fer-MO1 injected embryos failed to properly organize the dorsal aorta (DA) and cardinal vein (CV) regions (A,B), and had fewer ISV structures form (white arrowheads), when compared to the control MO injected embryos (E,F). Additionally, at similar time points in the absence of Fer kinase, hematopoietic precursor cells formed in the region of the DA but failed to circulate $(\mathbf{C}, \mathbf{D})$ (control MO- $(\mathbf{G}, \mathbf{H})$ ). Vasculature was visualized using fli1::nEGFP and hematopoietic cells were visualized using gata1::dsRed. In $(\mathbf{C}, \mathbf{D}, \mathbf{G}, \mathbf{H})$, punctate dots indicate stationary cells, while continuous lines indicate moving cells. Time points are at 30 somites $(\sim 28 \mathrm{hpf})$ for $(\mathbf{A}, \mathbf{C}, \mathbf{E}, \mathbf{G})$ and $48 \mathrm{hpf}$ for $(\mathbf{B}, \mathbf{D}, \mathbf{F}, \mathbf{H})$. (Note: some cells in appear overexposed due to the abundance of overlapping cells in one region.) The quantitative PCR showed that the expression of hematopoietic precursor genes (scl, gata1, notch1a, notch1b, notch3, c-myb) were increased in the absence of Fer kinase activity (runx1 is decreased early but recovers by 30 somites), while genes expressed in the vascular endothelium remained generally unaffected (fli1, $k d r l / f l k 1)$. The cell-cell adhesion complex component, $c d h 5$ (VE-cadherin) expression was unaffected in the absence of Fer kinase (I). (black bars indicate Fer MO at 8 somites, gray bars indicate Fer MO at 28 somites, * indicate not done). The dotted line denotes the threshold for up-regulated expression, when normalized to the wildtype expression levels, which was set at a value of 1 on the $y$-axis. 
We then tested the hypothesis that the lack of circulating erythrocytes in the absence of Fer was due primarily to defective vasculogenesis. By measuring different aspects of the trunk vasculature, we determined that in fer-MO1 embryos, at 30 somites, there was a significant decrease in the diameter of the dorsal aorta (DA) (Figure 5A, red arrows) and a loss of migrating cells into the intersegmental vessel (ISV) region (Figure 5A, white arrowhead), when compared to control MO embryos at the same stage (Figure 5B). Embryos lacking Fer kinase activity had a mean DA diameter of $4.93 \mu \mathrm{m}$, compared to $17.03 \mu \mathrm{m}$ for control MO injected embryos (Figure $5 \mathrm{C}, n=7$ per treatment, $p=1.91 \mathrm{e}-14$ ). Additionally, the number of cells migrating from the dorsal aorta into the region of the intersomitic boundaries was 1.78 cells per ISV in fer-MO1 embryos, less than half as many as the control MO embryos, which had 4.86 cells per ISV (Figure $5 \mathrm{D}, n=25$ per treatment, $p=1.42 \mathrm{e}-34$ ).

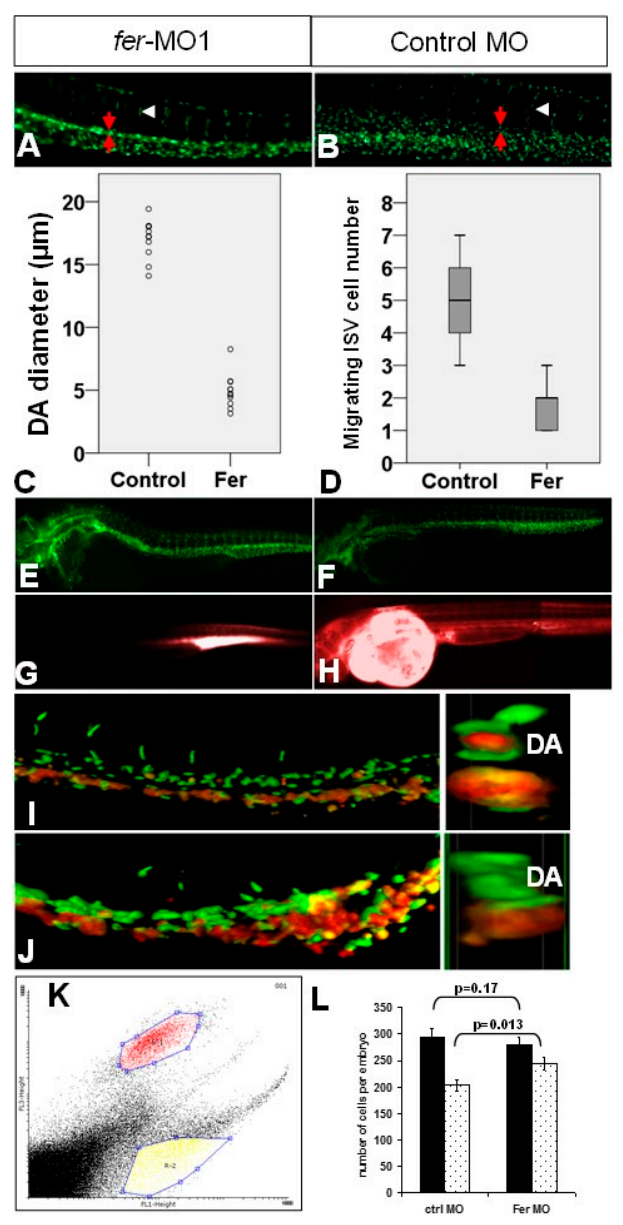

Figure 5. The loss of Fer kinase function resulted in vascular tubulogenesis defects. The loss of Fer kinase function decreased the diameter of the dorsal aorta $(\mathbf{A}, \mathbf{C})$ and resulted in fewer migrating cells into the ISV regions (D) at 30 somites (Control embryos (B-D). Rhodamine-Dextran injections into DA resulted in no visible dye circulation in Fer deficient embryos ((E), fli1::nEGFP, (G), Rhodamine), when compared to control embryos ((F), fli1::nEGFP, (H), Rhodamine). Confocal microscopy images demonstrated a concurrent loss of vasculature organization in the region of the DA and gain of hematopoietic precursors at $26 \mathrm{hpf}((\mathbf{I})$, control MO, (J), fer-MO1). The right images in (I,J) are digital cross-sections, taken approximately midway through the image; z-stacks showed no gata1::dsRed signal in the region that should be the inner-DA. The FACS analysis showed a shift in the number of gata1::dsRed cells, along with a loss of vascular endothelial population ((K), gated regions of non-overlapping, fli1a::nEGFP and gata1::dsRed cells, (L), quantitative plot showing differences in the cell population from $(\mathbf{K})$ in the presence/absence of Fer kinase activity). 
With a significantly smaller DA diameter and fewer cells migrating into the intersegmental boundaries, we then asked whether the vasculature that did form in the trunk region was undergoing tubulogenesis. We performed injections of a Rhodamine-Dextran conjugate into the dorsal aorta and sinus venosus regions of morpholino injected embryos (fer and control). With the severity of the disorganized posterior trunk vasculature using $0.5 \mathrm{mM}$ fer-MO1, we titrated the $\mathrm{MO}$ concentration and determined that at $1 \mathrm{~nL}$ of $0.25 \mathrm{mM}$ MO we were able to observe a higher level of organization, with a larger DA and more cells migrating in the intersegmental boundary regions (Figure 5E, control $\mathrm{MO}-$ Figure 5F). Thus, we used this lower concentration of MO to determine whether, even in the presence of increased normal vasculature organization, there was proper tube formation in the absence of Fer kinase. In control MO injected embryos, we observed normal distribution of the Rhodamine dye within fifteen minutes post-injection $(n=12)$ (Figure $5 \mathrm{H})$. However, in the fer-MO1 injected embryos, the dye never migrated beyond the area of injection, at up to one hour post-injection $(n=9)$ (Figure $5 \mathrm{G})$. Our results suggest that, even in the presence of vasculature and a beating heart, there is not a sufficient amount of organized, open tubes within the trunk endothelium, to allow for proper circulation of existing blood cells in the absence of Fer kinase function. (sinus venosus injection data resulted in similar loss of dye circulation [37].

Using confocal microscopy we were able to support our previously observed phenotype by showing that in the same embryo, the absence of Fer caused both defective DA/CV remodeling and ISV cell migration (fli1a::nEGFP), as well as increased populations of gata1::dsRed expressing cells in the DA (Figure 5J, control embryo-Figure 5I) ( $n=10$ per condition). By analyzing the confocal images in a cross section, we were able to show that fer-MO1 embryos lacked gata1::dsRed cells migrating through what is normally the lumen of the DA, in contrast to control MO injected embryos (Figure 5J,I respectively, right panel). This data further supports the proposal that there are no circulating hematopoietic cells due to improper tubulogenesis within the trunk vasculature.

Our data, showing either a loss of hemoglobin expressing erythrocytes, or a pooling of existing erythrocytes, in addition to a lack of vascular organization, caused us to question whether there was a shift in the number of cells within these populations in the absence of Fer. We tested this by performing a fluorescence activated cell sorting (FACS) analysis with embryos containing both the fli1a::nEGFP and gata1::dsRed expressing cells. fer-MO1 embryos were separated into the two categories of severity described earlier, where one category of embryos had a pooling of hematopoietic cells and another, more severe category contained no observable hematopoietic cells under white light microscopy. Since the majority of embryos contained the pooled hematopoietic cells, we chose to use only those for the FACS analysis.

To clarify the fluorescent populations, the gated regions, represented in Figure $4 \mathrm{~K}$, demonstrate that we counted cell populations that reflected the expression of either fli1a (nEGFP) or gata1 (dsRed). Since these are live cells, we could not avoid the fact that dsRed goes through an intermediate state that fluoresces in the nEGFP spectrum while folding, and thus, appears to be both nEGFP and dsRed positive [38,39]. However, because the cells contain a combination of dsRed and GFP-like fluorescence, we were able to distinguish it from the fli-1a::nEGFP only population (Figure 5K). When we tested injected embryos using a FACS analysis of the gated regions, the fer-MO1 embryos at 30 somites showed a significant increase in the number of gata1::dsRed positive cells per embryo, from 203 in the control embryos, to 244 in the fer-MO1 embryos $(p=0.013)$ and, conversely, no effective change in the number of fli1a::nEGFP, from 294 cells per embryo in the control embryos, to 280 cells per embryo in the absence of Fer $(p=0.17)$ (Figure 5L). Although this increase in cell number appears moderate, it is reasonable based on previous studies examining the conversion of vascular precursors in the dorsal aorta into erythrocytes [40]. Thus, we further investigated whether the endothelial cells are converted to erythrocytes or there is excess proliferation within the erythrocyte population.

With a distinct link between the loss of differentiated erythrocytes and lack of proper vasculogenesis, we next sought to determine whether there were gene expression changes in the early genes that specify the direction of differentiation beyond the hemangioblast cell populations early 
in development. We examined the expression of erythrocyte determining genes at the 6 somite stage of all embryos and found that gata1 and scl, both normally expressed in the lateral plate mesoderm, appear to have slightly decreased levels and a discontinuous pattern in the fer-MO1 embryos (Figure 6B), when compared to control MO embryos (Figure $6 \mathrm{~A})(n=20 / 26$ and 25/32 respectively). Although the shape of the embryos appears wider, due to the convergent extension defects that lead to a shortening along the anterior-posterior axis of the embryo, the overall expression levels of the gata1 and scl genes appear to be mostly intact.

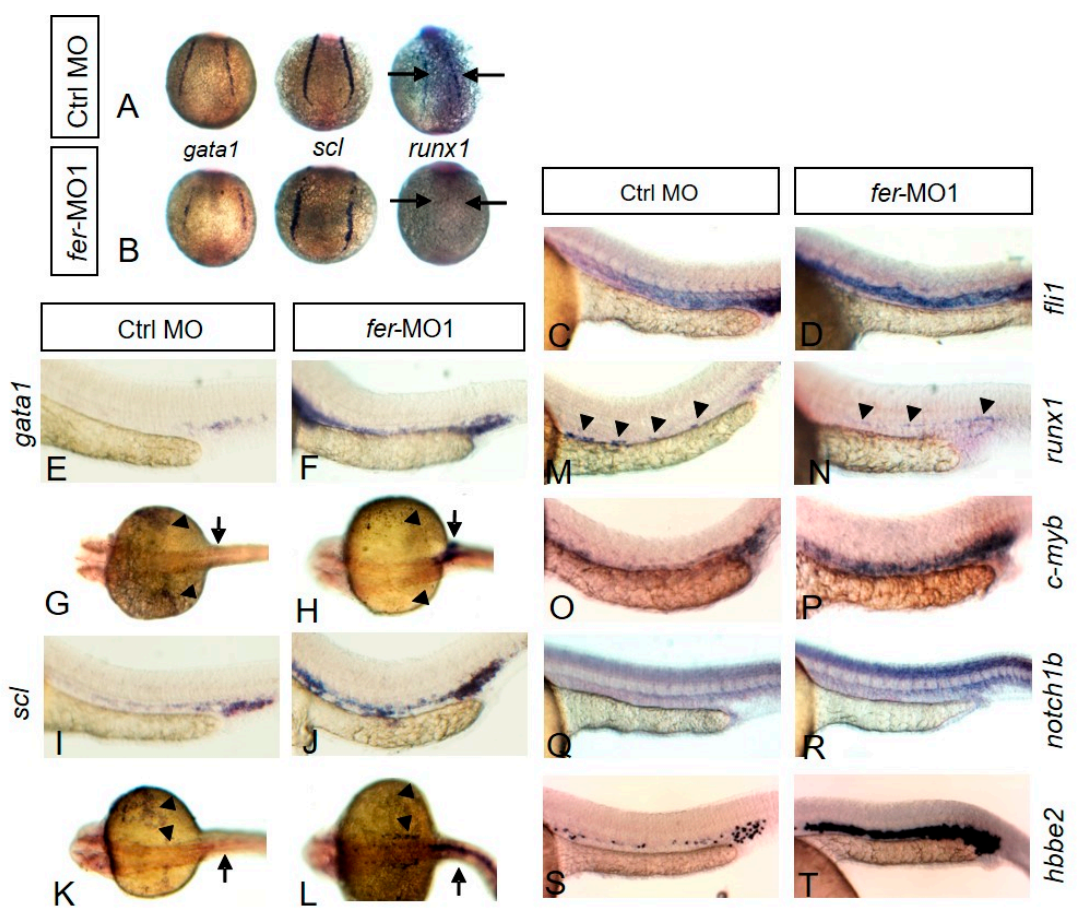

Figure 6. Fer kinase is required for proper expression patterns of hematopoietic genes. In situ hybridization showed the expression of gata1, scl and runx1 at the 6 somite stage in the region of the lateral plate mesoderm. Control embryos are shown in (A) while fer-MO1 embryos are shown in (B). Arrows point to the region of runx1 expression. At 30 somites, the expressions of fli1 (C,D), gata1 (E-H), $\operatorname{scl}(\mathbf{I}-\mathbf{L}), \operatorname{runx} 1(\mathbf{M}, \mathbf{N}), c-m y b(\mathbf{O}, \mathbf{P}), \operatorname{notch} 1 b(\mathbf{Q}, \mathbf{R})$, and $h b b e 2(\mathbf{S}, \mathbf{T})$ are shown.

However, when we examined expression of runx1, shown to be required for proper erythrocyte development and vasculogenesis [41], we observed a severe decrease in the expression of the posterior lateral plate mesoderm in the absence of Fer $(n=23 / 36)$ (Figure 6B) when compared to control embryos (Figure 6A-black arrows).

Due to the altered nature in the expression of gata1, scl and runx1 earlier, we then examined the later expression of genes involved in both vasculogenesis and hematopoiesis in the region of the ICM. At 30 somites, the vascular endothelium marker, fli1, was expressed at normal levels but showed that in 79.1 percent of fer-MO1 embryos there was a general lack of organization in the trunk region, with no observable structural differentiation within the DA and CV regions, as well as no migrating ISV cells $(n=34 / 43)$ (Figure 6D), when compared to control embryos at the same stage $(n=30)$ (Figure 6C).

Probes against hematopoietic genes, such as gata1 $(n=44 / 52)$ (Figure $6 \mathrm{~F}, \mathrm{H}), \operatorname{scl}(n=47 / 55)$ (Figure 6J, L), c-myb ( $n=34 / 41)$ (Figure 6P) and $h b b e 2(n=41 / 48)$ (Figure 6T) stained a larger population of cells in the absence of Fer kinase, with the region of cells expressing these markers expanded in the anterior direction (control $\mathrm{MO}$ is shown in Figure $6 \mathrm{E}, \mathrm{G}$ (gata1), $\mathrm{I}, \mathrm{K}(s c l), \mathrm{O}(c-m y b), \mathrm{S}$ (hbbe2) respectively), suggesting either an up-regulation of expression with these genes or an increase in the number of cells expressing these genes. We also observed a partial recovery of runx1 expression $(n=30 / 38)$ 
(Figure $6 \mathrm{~N}$ ), when compared to the control embryos $(n=40)$ (Figure $6 \mathrm{M}$ ). We next examined each of these genes using quantitative PCR and confirmed an increase in expression correlating to that observed with our in situ hybridization analyses, with increases in expression, ranging from 1.5 to 2.5 fold, over control embryos at the same stage of development (Figure 4I). One notable exception was that of runx1, which appears to be expressed at normal levels, which again, is in agreement with the in situ hybridization results we observed.

The lack of migrating ISV cells during development suggested to us that there may be aberrant Notch function in the absence of Fer, as Notch has been well known to regulate the formation of ISVs $[42,43]$. Initially, we thought that perhaps an overexpression of a Notch signal might be responsible for the defects related to the absence of Fer. We then investigated the expression levels of notch1a, notch $1 b$ and notch 3 during development in fer-MO1 embryos at two time points (8 somites and 28 somites) using quantitative PCR (Figure 4I). Surprisingly, notch3 expression was not altered; however, levels of both notch1a and notch $1 b$ were both decreased by more than half the normal levels at 8 somites, and elevated in excess of 1.5 fold at 28 somites. Thus, we examined notch $1 b$ via WISH and observed that, consistent with our qPCR data, it was indeed up-regulated in the absence of Fer, when compared to control MO embryos, in the trunk region (Figure 6R,Q, respectively) and the head [37].

\subsection{Fer Kinase-Dependent and-Independent Activity during Development}

To further investigate how Fer kinase functions during development, we tested whether the kinase activity of Fer was required in specifying endothelium and hematopoietic cells. We generated two separate point mutations that have previously been shown to effectively inactivate the kinase activity of Fer in mice (SH2 and TyrKin mutations) and worms (TyrKin mutation) [12,16]. The first point mutation was in the SH2 domain and changed a tryptophan to a cysteine, while the second and third mutations converted an aspartic acid to an arginine, and lysine to arginine, respectively, in the tyrosine kinase domain (Figure 7O, Western blot confirmation of protein expression shown in Supplementary Figure S1). We then attempted to rescue the fer-deficient phenotypes by co-injecting fer-MO1 $(0.25 \mathrm{mM})$ with fer mRNA (wildtypes or containing either point mutation). It is important to note that we used a cloned cDNA for fer, thus eliminating the possibility that the mRNA might be targeted by the splice blocking $\mathrm{MO}$ (which exclusively targets an intron sequence). In three independent experiments, wildtype fer mRNA was able to rescue both the vascular and hematopoietic defects in the absence of endogenous Fer kinase activity, when compared to a control co-injection of fer-MO1 and fer anti-sense mRNA (Supplementary Figure S2). The DA and ISV organization allowed for proper tubulogenesis to take place, as injection with the rhodamine-dextran dye showed circulation throughout the embryo $(n=9)$ (Figure 7B,E) compared to fer-MO1 alone (Figure 7A,D). Additionally, in situ hybridization demonstrated that expression of hematopoietic directing genes such as runx1 ( $n=29 / 33)$, gata1 ( $n=32 / 37)$, and hbbe2 $(n=47 / 52)$ were restored to normal spatio-temporal expression patterns (Figure $7 \mathrm{H}, \mathrm{K}, \mathrm{N}$ ), when compared to fer-MO1 alone (Figure 7G,J,M).

Interestingly, both point mutants were able to rescue tubulogenesis within the vasculature, with circulation of the Rhodamine-Dextran dye evident within fifteen minutes of injection $(n=12)$ (Figure 7C,F-TyrKin (D744R) point mutant results shown only). However, neither of the Fer kinase inactive point mutants (denoted as Fer KD) were able to rescue the hematopoietic cell population defects, as evidenced by the fact that there was no significant difference between the fer-MO1 embryos and the fer-MO1/fer mRNA (WT or KD) injected embryos, with respect to expanded expression of runx1 $(n=25 / 31)$, gata1 $(n=23 / 28)$ and hbbe2 $(n=41 / 45)$ (Figure 7I,L,P). These data strongly suggest that there are both kinase-dependent and independent functions to Fer that are required during normal development in zebrafish. Specifically, we found that the Fer kinase-dependent activity was associated with the expansion of erythrocyte gene expression, while the kinase-independent properties of Fer were required in the organization of the vasculature. 


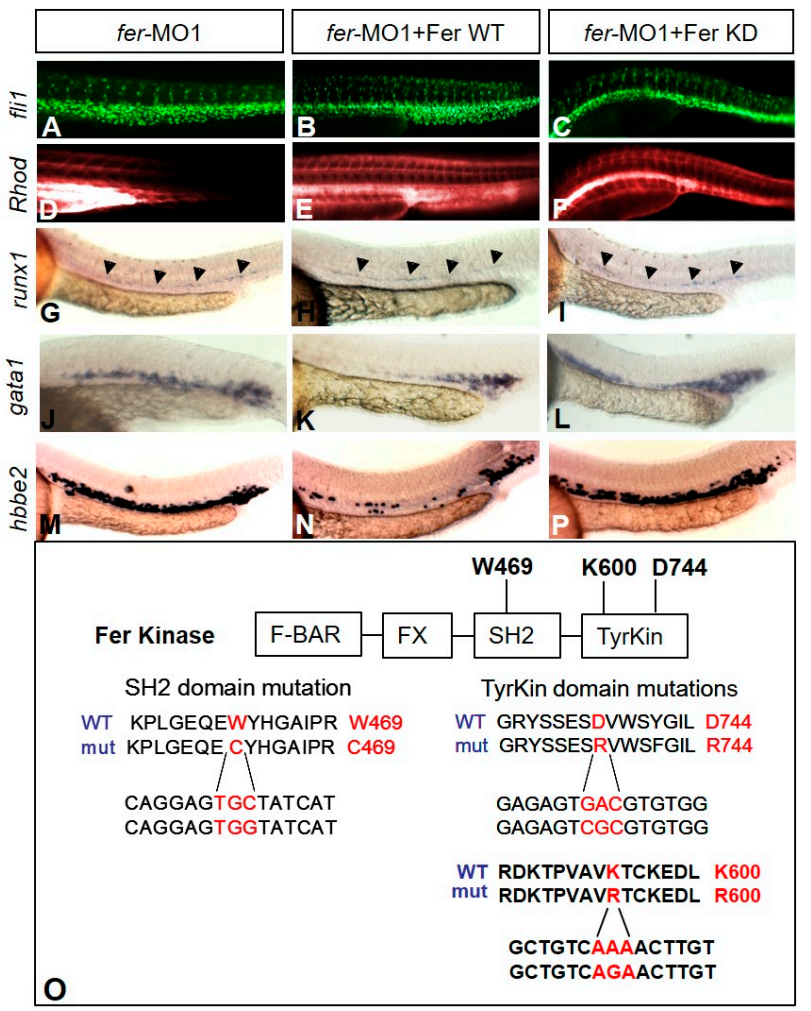

Figure 7. Kinase-inactive Fer rescues vascular tubulogenesis but not hematopoiesis gene expression defects. The injection of fer mRNA and fer-MO1 into fli1a::nEGFP embryos results in increased cell migration into the ISV regions ((B) - WT, (C) - kinase inactive (KD)) when compared to fer-MO1 alone (A), and rescues tube formation ((E) - WT, (F) - KD, Rhodamine-Dextran circulation after 15 min, when compared to fer-MO1 alone (D)). Wild type Fer ameliorates defects in erythrocyte expansion, as observed with runx1 (H), gata1 (K) and hbbe2 (N), while inactive Fer does not ((I,L,P) respectively). fer-MO1 alone is shown in $(\mathbf{G}, \mathbf{J}, \mathbf{M})$ respectively. Embryos were examined at 30 somites ( $28 \mathrm{hpf})$. Domains of Fer kinase in zebrafish, showing the highly conserved tryptophan and aspartic acid residues, in the $\mathrm{SH} 2$ and tyrosine kinase domains, respectively, are shown. Mutating either tryptophan to cysteine (W469C), aspartic acid to arginine (D744R) or lysine to arginine (K600R) resulted in the loss of kinase activity for Fer. The amino acid sequence is shown on top, with the corresponding DNA sequence changes below ((O), Fer KD expression confirmation shown in Supplementary Figure S1).

\subsection{Fer Stabilizes Notch Signaling during Vasculogenesis but Not Hematopoiesis}

Finally, due to the established links with Notch signaling, regulating both hematopoietic and angiogenic signaling in zebrafish [44], along with our data showing increased expression of the notch $1 b$ gene in the absence of Fer, we hypothesized that Fer functions in regulating Notch signaling during vasculogenesis and hematopoiesis. It has been shown that increased Notch activity suppresses migration of endothelial cells into the ISV regions from the DA [45], as well as facilitates expansion of the growing erythrocyte populations [46]. Additionally, previous reports have demonstrated that the absence of Fer destabilizes cadherin complexes, and thus, cell-cell adhesions [16,21,24], which would have a downstream effect on juxtacrine signaling. Knowing this, we tested our hypothesis that, although we observed increased notch1 expression, a portion of the phenotype in the absence of Fer could be due to the prevention of juxtacrine mediated Notch signaling as a potential consequence of lost cell-cell adhesion.

Thus, we attempted to rescue the fer-MO1 phenotype, by activating Notch, regardless of cell-cell adhesion. We co-injected mRNA expressing the activated form of Notch (NICD-Notch Intra-Cellular Domain) along with mRNA expressing either wildtype or kinase inactive Fer (WT or KD) (NICD 
expression confirmed via Western analysis is shown in Supplementary Figure S1). After titrating amounts of both NICD and fer mRNA, to eliminate non-specific, toxic effects, we found that injecting 10-15 pg of NICD mRNA with the control MO $(0.5 \mathrm{mM})$ had no effect on the development of hematopoietic cells or vasculogenesis $(n=52)$ (Figure $8 \mathrm{~A}-\mathrm{C}$, respectively), as did injection with the control MO alone (data not shown). Knocking down Fer function resulted in an expansion of hematopoietic markers such as gata1 and $s c l$ (Figure $8 \mathrm{M}, \mathrm{N}$, respectively). Additionally, reduced Fer function also inhibited ISV sprouting, as observed with fli1 expression (Figure 8O, arrowheads). However, when co-injected with the fer-MO1 $(0.5 \mathrm{mM})$, the activated form of Notch was able to partially rescue vasculogenesis, as measured by the presence of fli1+ cells migrating into the ISV region ( $58.7 \%$ rescue, $n=63$ ) (Figure $8 \mathrm{~L}$-arrowheads), but had no effect on the hematopoietic gene expression defect $(87.2 \%$ defective, $n=55)$ (Figure $8 \mathrm{~J}, \mathrm{~K}$ ), suggesting that expansion of hematopoietic cells requires Fer kinase activity, in addition to activated Notch. The ability of NICD to rescue vascular endothelial cell organization was further enhanced when co-injected with the wildtype version of Fer $(82.7 \%$ rescue, $n=58)$ (Figure $8 \mathrm{~F}$ ), and was also sufficient to rescue the hematopoietic gene expression defect $(86.9 \%$ rescue, $n=61$ ) (Figure $8 \mathrm{D}, \mathrm{E})$. Surprisingly, the NICD was also able to rescue the Fer deficient vasculogenesis defect when co-injected with the kinase-inactive Fer (Figure 8I) almost as effectively as with the wildtype Fer (76.6\% rescue, $n=47)$, but not the expanded hematopoietic gene expression $(79.1 \%$ defective, $n=53$ ) (Figure $8 \mathrm{G}, \mathrm{H}$ ). We were not able to determine whether the erythrocyte gene expansion was primarily due to up-regulated Notch mediated specification or hyperactivated proliferation. However, these results suggest that, in contrast to hematopoietic populations, the vasculogenic organization events, via Notch activation, are either enhanced, or stabilized, in the presence of Fer, regardless of Fer kinase activity.

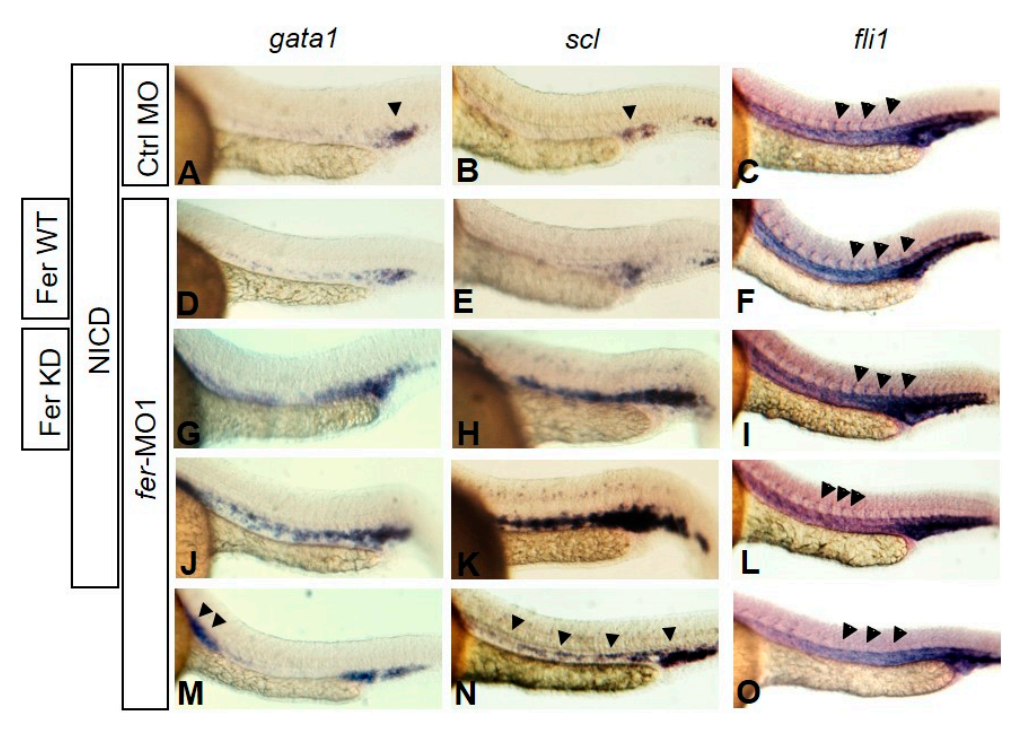

Figure 8. Fer functions independently of Notch for erythrocyte population expansion but not intersomitic vessel formation. Co-injection of the Notch Intracellular Domain (NICD), along with wildtype (WT) or kinase-inactive (KD) Fer, showed that active Notch partially rescues vascular migration in the absence of Fer (fli1: (F)—WT, (I)—KD), but not excess erythrocyte proliferation (gata1: (D), WT, (G), KD; scl: (E), WT, (H), KD), when compared to fer-MO1 embryos containing only the NICD (J,K,L). Control MO embryos with injected NICD show normal gene expression of gata1 (A), $s c l$ (B) and fli1 (C). fer-MO1 alone-gata1 (M), scl (N) and fli1 (O). Embryos examined at 30 somites ( 28 hpf).

\section{Discussion}

The challenges in uncovering functions of Fer kinase during vertebrate development have remained somewhat elusive, due to issues with obtaining a genomic knockout of the gene. 
Although evidence has been reported as to the function of Fer kinase during mouse development, much of the data has been obtained using a kinase inactive knock-in version of the gene, which results in viable mice, implying Fer may serve mainly in redundant roles during development [12]. We have observed that in the absence of Fer kinase in zebrafish, embryonic development is arrested by $72 \mathrm{~h}$ post fertilization, in agreement with what was previously reported by Paardekooper Overman, et al. [20]. Here we reported a novel defect with vasculogenesis and erythrocyte differentiation in the absence of Fer kinase. Additionally, we demonstrated the presence of kinase-independent activity of Fer, which may partially explain the viability of the knock-in, kinase inactive Fer mouse [12]. Furthermore, similar to our results, under normal conditions, Fer kinase expression has been observed in hematopoietic precursors in mice [4]. The Fes/Fps kinase has been shown to redundantly regulate hematopoiesis, along with Fer, through Stat5 and Erk [47]; however, the in vivo role of Fer in the differentiation and proliferation of this cell type has not been previously characterized in developing vertebrate embryos.

The role of Runx1 in zebrafish development has been well characterized, with the mutant being initially reported to prevent both definitive hematopoiesis and vessel development [41], and more recently runx 1 was shown to be expressed in early hemogenic endothelial cells [48]. That study showed a loss of circulation, due to improper vessel growth and an accumulation of erythrocyte precursors. This is similar to what we observed in our experiments knocking down Fer kinase activity. It has also been reported that Runx1 is tyrosine phosphorylated by Src family kinases in a manner that is required for proper hematopoiesis to occur [49]. The similar phenotypes, linked by our data, showing an early decrease, followed by a recovery of runx1 expression, suggest that there is a finely tuned regulation of Runx1 function during development, possibly at the level of phosphorylation, if not by gene expression levels.

Our experiments suggest that, in the absence of Fer, there is a defect in the Notch/Runx1 pathway, which results in an increase in gata 1 and $c-m y b$ expression, and a concomitant increase in erythrocytes. This finding is supported by data in which Cai et al. reported that an AML (Runx1) haploinsufficent mouse model resulted in the early emergence of hematopoietic stem cells [50]. Furthermore, a conditional Runx1 deletion in mice resulted in the depletion of later emerging, adult hematopoietic stem cell populations [51]. Since Notch activates Runx1, it could be that, in the absence of Fer, the normal ratio of hematopoietic and endothelial precursors in later embryos is shifted, in this case due to a hyperactive Notch signal that enhanced the number of erythrocytes at the expense of endothelium prior to the onset of definitive hematopoiesis, a model suggested by [52]. However, our results show that there is an increase in the erythrocyte gene expression without a corresponding major decrease in vascular endothelial cells, similar to the increase in hematopoietic stem cell marker production with the overexpression of the NICD, reported by Burns et al. [44].

Although we could not conclude whether it was expanded, the determination versus proliferation of erythrocyte precursors in the absence of Fer, supported a cellular proliferation role, rather than specification, as it has been previously shown in that Fer kinase is required for proper cell cycle control in models ranging from nematode endoderm proliferation and seam cell division $[26,27]$ to acute myeloid leukemia cell lines [53]. Thus, it is possible that under normal conditions during development, Fer plays a role in regulating the expansion of the trunk hematopoietic cells via Notch signaling.

In the absence of Fer kinase activity, we observed that proper heart development was arrested with the presence of non-circulating erythrocytes, in both heart chambers, along with pericardial edema (Figure 2B-H), which is similar to what was reported by Mitchell, et al. with the knockdown of VE-cadherin in zebrafish [54]. However, since our data showed that the knockdown of Fer kinase caused severe defects in the trunk vasculature, which was not observed with the knockdown of VE-cadherin in Mitchell, et al., it is likely that the fer-MO1 defect is not through decreased cadherin expression (Figure 4I), but in the destabilization of cadherin-mediated adhesion complexes. A critical role for Fer in stabilizing cadherin complexes during development has been previously shown with Fer homologues in both nematodes and flies [16,24]. In parallel with cadherin complex stability, the defect 
we observed could also be due to a migration defect that is dependent on integrin complexes between the plasma membrane and the extracellular matrix used by migrating ISV cells as they move along the intersomitic boundaries. In fact, it has been reported that both Fes/Fps kinase family members and integrin linked kinases (ILK) regulate survival and migration in vascular endothelium, during mouse and zebrafish development, respectively $[55,56]$. Thus, it is reasonable to hypothesize that Fer kinase mediates activity in the switch from adhesion to migration, as it has previously been shown to engage in cross-talk between cadherin and integrin complexes [33,57].

Although we observed an increase in notch1 expression, endogenous Notch activity may be abrogated by a loss of cell-cell adhesion, as occurs with the loss of cadherin complex stability in the absence of Fer [16,24], which would disrupt juxtacrine dependent processes. It is also possible that the loss of hematopoietic cells that we observed with Fer knockdown is due to blockage of circulatory flow, such as has been reported by North et al. [58]. Alternatively, it could be that Fer functions, in part, to regulate the emergence of hematopoietic gene expression, which would be consistent with the expression of notch1b and emergence of HSCs, reported by Kim et al. [59], and that even in the absence of flow, those genes can be activated. However, the vasculogenesis defects we observed in Fer deficient embryos are similar to that reported in the absence of gridlock, a gene downstream of Notch that is required for proper vasculogenesis during zebrafish development [43]. Furthermore, Notch signaling normally acts to regulate angiogenic behavior, such that when Notch activity is lost, there is excess proliferation and migration within the endothelial cell lineage $[45,60]$. More recently, it was shown that notch $1 b$ promotes arterial cell fate and prevents tip cell fate, thus sprouting into the ISV from the DA [61]. Our observation that in the absence of Fer kinase, there was a lack of endothelial cell migration out of the DA, combined with an overexpression of notch1b, suggests a role for Fer in regulating vascular cell migration. Two likely possibilities in which the absence of Fer would allow the overexpression of Notch in the DA are: (1) suppressed endothelial fates, thereby facilitating a switch to hematopoietic fate, or (2) excess Notch simply prevents initial migration into the ISVs and the hematopoietic expansion occurs in a distinct manner, separate from endothelial cell migration. Any migrating cells moving into the ISVs, however, would likely not be stabilized, due to a potential loss of cell-cell contacts (normally stabilized via Fer).

Finally, the emergence of kinase inactive roles for many protein kinases has become an intriguing topic in recent years. In the case of Fer, the finding that a kinase inactivating knock-in allows sufficient function for development and viability in mice suggests kinase-independent roles for Fer [12]. Although it is possible that defects observed in the absence of Fer are primarily due to the loss of cell adhesion, combined with up-regulation of Notch1, our data also suggest kinase-dependent and independent roles of Fer, which are distinct along the lines of erythrocyte expansion and endothelial adhesion/migration. We suggest a kinase active role for Fer that regulates expansion of erythrocyte precursors, which is enhanced in the presence of activated Notch. Additionally, a kinase inactive function of Fer is necessary in organizing the vasculature, by regulating the Notch signaling that facilitates migrating ISV cells.

The concept of a balance in Fer kinase activity has been supported in other studies, such as over-expression data in metastatic breast cancer and gain of function mutation data from fruit flies [24,62]. In both cases, excess Fer kinase activity destabilized cell-cell adhesion and promoted a disorganized migration of cells, suggesting there is an optimum range of Fer activity that is critical to proper cell function. However, neither study examined the possibility that Fer may function, at least partially, in a kinase-independent manner. This additional function was later shown to be present in both mice [12] and nematodes [16].

\section{Conclusions}

Taken together, our results suggest that Fer kinase activity regulates a finely tuned balance that, when lost, results in an increase in the erythrocyte population, while at the same time, exerts a kinase independent function that facilitates cellular organization in the vascular endothelium. This function 
of Fer is likely through stabilization of adhesion complexes at the plasma membrane, such as cadherin and integrin complexes, which mediates critical juxtacrine signaling mechanisms. Future studies will likely identify the protein interactions for Fer, which will further clarify the phosphorylation events in proliferation activity as well as kinase-independent, direct interactions facilitating cell-cell adhesion in the regulation of juxtacrine mechanisms, such as the Notch pathway, in vascular endothelial cell migration.

Supplementary Materials: The following are available online at www.mdpi.com/2079-7737/6/4/40/s1, Figure S1: Fer protein expression analysis; Figure S2: Control MO+fer anti-sense mRNA rescue; Table S1: qPCR oligos; Video S1: Fer Kinase MO-1 — circulating blood cells; Video S2: Fer Kinase control MO—circulating blood cells; Video S3: Fer Kinase MO-1—arrest of proper heart looping along with pericardial edema; Video S4: Fer Kinase control MO-arrest of proper heart looping along with pericardial edema.

Acknowledgments: We would like to thank Don Kane (Western Michigan University) and Cecilia Moens (Fred Hutchinson Cancer Research Center) for WISH probe plasmids. We are also grateful to Don Kane and Rachel Warga, as well as members of the Putzke and MacKeigan laboratories, for helpful discussions regarding experiments and data analysis. This work was funded in part by a grant by the MJ Murdock Trust (APP), a grant from the Harry A and Margaret D Towsley Foundation (APP), NSF-REU 0754293 and NSF-MRI 1335890.

Author Contributions: Aaron P. Putzke conceived and designed the experiments; Emily M. Dunn, Elizabeth J. Billquist, Amy L. VanderStoep, Phillip G. Bax, Laura M. Westrate, Lisa K. McLellan, Shelby C. Peterson, performed the experiments; Emily M. Dunn, Elizabeth J. Billquist, Amy L. VanderStoep, Phillip G. Bax, Laura M. Westrate, Lisa K. McLellan, Shelby C. Peterson analyzed the data; Jeffrey P. MacKeigan contributed reagents/materials/analysis tools. All authors contributed to writing the paper.

Conflicts of Interest: The authors declare no conflict of interest. The funding sponsors had no role in the design of the study; in the collection, analyses, or interpretation of data; in the writing of the manuscript, and in the decision to publish the results.

\section{References}

1. Coultas, L.; Chawengsaksophak, K.; Rossant, J. Endothelial cells and vegf in vascular development. Nature 2005, 438, 937-945. [CrossRef] [PubMed]

2. Thisse, B.; Thisse, C. Functions and regulations of fibroblast growth factor signaling during embryonic development. Dev. Biol. 2005, 287, 390-402. [CrossRef] [PubMed]

3. Rauch, J.; Volinsky, N.; Romano, D.; Kolch, W. The secret life of kinases: Functions beyond catalysis. Cell Commun. Signal. 2011, 9. [CrossRef] [PubMed]

4. MacDonald, I.; Levy, J.; Pawson, T. Expression of the mammalian c-fes protein in hematopoietic cells and identification of a distinct fes-related protein. Mol. Cell. Biol. 1985, 5, 2543-2551. [CrossRef] [PubMed]

5. Hao, Q.L.; Heisterkamp, N.; Groffen, J. Isolation and sequence analysis of a novel human tyrosine kinase gene. Mol. Cell. Biol. 1989, 9, 1587-1593. [CrossRef] [PubMed]

6. Pawson, T.; Letwin, K.; Lee, T.; Hao, Q.L.; Heisterkamp, N.; Groffen, J. The fer gene is evolutionarily conserved and encodes a widely expressed member of the fps/fes protein-tyrosine kinase family. Mol. Cell. Biol. 1989, 9, 5722-5725. [CrossRef] [PubMed]

7. McPherson, V.A.; Everingham, S.; Karisch, R.; Smith, J.A.; Udell, C.M.; Zheng, J.; Jia, Z.; Craig, A.W. Contributions of $\mathrm{f}$-bar and sh2 domains of fes protein tyrosine kinase for coupling to the fcepsilonri pathway in mast cells. Mol. Cell. Biol. 2009, 29, 389-401. [CrossRef] [PubMed]

8. Craig, A.W.; Zirngibl, R.; Greer, P. Disruption of coiled-coil domains in fer protein-tyrosine kinase abolishes trimerization but not kinase activation. J. Biol. Chem. 1999, 274, 19934-19942. [CrossRef] [PubMed]

9. Kim, L.; Wong, T.W. The cytoplasmic tyrosine kinase fer is associated with the catenin-like substrate pp120 and is activated by growth factors. Mol. Cell. Biol. 1995, 15, 4553-4561. [CrossRef] [PubMed]

10. Kim, L.; Wong, T.W. Growth factor-dependent phosphorylation of the actin-binding protein cortactin is mediated by the cytoplasmic tyrosine kinase fer. J. Biol. Chem. 1998, 273, 23542-23548. [CrossRef] [PubMed]

11. Priel-Halachmi, S.; Ben-Dor, I.; Shpungin, S.; Tennenbaum, T.; Molavani, H.; Bachrach, M.; Salzberg, S.; Nir, U. Fer kinase activation of stat3 is determined by the n-terminal sequence. J. Biol. Chem. 2000, 275, 28902-28910. [CrossRef] [PubMed] 
12. Craig, A.W.; Zirngibl, R.; Williams, K.; Cole, L.A.; Greer, P.A. Mice devoid of fer protein-tyrosine kinase activity are viable and fertile but display reduced cortactin phosphorylation. Mol. Cell. Biol. 2001, 21, $603-613$. [CrossRef] [PubMed]

13. Lennartsson, J.; Ma, H.; Wardega, P.; Pelka, K.; Engstrom, U.; Hellberg, C.; Heldin, C.H. The fer tyrosine kinase is important for platelet-derived growth factor-bb-induced signal transducer and activator of transcription 3 (stat3) protein phosphorylation, colony formation in soft agar, and tumor growth in vivo. J. Biol. Chem. 2013, 288, 15736-15744. [CrossRef] [PubMed]

14. Zoubeidi, A.; Rocha, J.; Zouanat, F.Z.; Hamel, L.; Scarlata, E.; Aprikian, A.G.; Chevalier, S. The fer tyrosine kinase cooperates with interleukin-6 to activate signal transducer and activator of transcription 3 and promote human prostate cancer cell growth. Mol. Cancer Res. 2009, 7, 142-155. [CrossRef] [PubMed]

15. Cetkovic, H.; Muller, I.M.; Muller, W.E.; Gamulin, V. Characterization and phylogenetic analysis of a cdna encoding the fes/fer related, non-receptor protein-tyrosine kinase in the marine sponge sycon raphanus. Gene 1998, 216, 77-84. [CrossRef]

16. Putzke, A.P.; Hikita, S.T.; Clegg, D.O.; Rothman, J.H. Essential kinase-independent role of a fer-like non-receptor tyrosine kinase in caenorhabditis elegans morphogenesis. Development 2005, 132, 3185-3195. [CrossRef] [PubMed]

17. Katzen, A.L.; Montarras, D.; Jackson, J.; Paulson, R.F.; Kornberg, T.; Bishop, J.M. A gene related to the proto-oncogene $\mathrm{fps} / \mathrm{fes}$ is expressed at diverse times during the life cycle of drosophila melanogaster. Mol. Cell. Biol. 1991, 11, 226-239. [CrossRef] [PubMed]

18. Paulson, R.; Jackson, J.; Immergluck, K.; Bishop, J.M. The dfer gene of drosophila melanogaster encodes two membrane-associated proteins that can both transform vertebrate cells. Oncogene 1997, 14, 641-652. [CrossRef] [PubMed]

19. Fischman, K.; Edman, J.C.; Shackleford, G.M.; Turner, J.A.; Rutter, W.J.; Nir, U. A murine fer testis-specific transcript (fert) encodes a truncated fer protein. Mol. Cell. Biol. 1990, 10, 146-153. [CrossRef] [PubMed]

20. Paardekooper Overman, J.; Preisinger, C.; Prummel, K.; Bonetti, M.; Giansanti, P.; Heck, A.; den Hertog, J. Phosphoproteomics-mediated identification of fer kinase as a target of mutant shp2 in noonan and leopard syndrome. PLOS ONE 2014, 9. [CrossRef] [PubMed]

21. Rosato, R.; Veltmaat, J.M.; Groffen, J.; Heisterkamp, N. Involvement of the tyrosine kinase fer in cell adhesion. Mol. Cell. Biol. 1998, 18, 5762-5770. [CrossRef] [PubMed]

22. Sangrar, W.; Gao, Y.; Scott, M.; Truesdell, P.; Greer, P.A. Fer-mediated cortactin phosphorylation is associated with efficient fibroblast migration and is dependent on reactive oxygen species generation during integrin-mediated cell adhesion. Mol. Cell. Biol. 2007, 27, 6140-6152. [CrossRef] [PubMed]

23. Yoneyama, T.; Angata, K.; Bao, X.; Courtneidge, S.; Chanda, S.K.; Fukuda, M. Fer kinase regulates cell migration through alpha-dystroglycan glycosylation. Mol. Biol. Cell 2012, 23, 771-780. [CrossRef] [PubMed]

24. Murray, M.J.; Davidson, C.M.; Hayward, N.M.; Brand, A.H. The fes/fer non-receptor tyrosine kinase cooperates with src42a to regulate dorsal closure in drosophila. Development 2006, 133, 3063-3073. [CrossRef] [PubMed]

25. Allard, P.; Zoubeidi, A.; Nguyen, L.T.; Tessier, S.; Tanguay, S.; Chevrette, M.; Aprikian, A.; Chevalier, S. Links between fer tyrosine kinase expression levels and prostate cell proliferation. Mol. Cell. Endocrinol. 2000, 159, 63-77. [CrossRef]

26. Mila, D.; Calderon, A.; Baldwin, A.T.; Moore, K.M.; Watson, M.; Phillips, B.T.; Putzke, A.P. Asymmetric wnt pathway signaling facilitates stem cell-like divisions via the nonreceptor tyrosine kinase frk-1 in caenorhabditis elegans. Genetics 2015, 201, 1047-1060. [CrossRef] [PubMed]

27. Putzke, A.P.; Rothman, J.H. Repression of wnt signaling by a fer-type nonreceptor tyrosine kinase. Proc. Natl. Acad. Sci. USA 2010, 107, 16154-16159. [CrossRef] [PubMed]

28. Li, H.; Ren, Z.; Kang, X.; Zhang, L.; Li, X.; Wang, Y.; Xue, T.; Shen, Y.; Liu, Y. Identification of tyrosine-phosphorylated proteins associated with metastasis and functional analysis of fer in human hepatocellular carcinoma cells. BMC Cancer 2009, 9. [CrossRef] [PubMed]

29. Miyata, Y.; Kanda, S.; Sakai, H.; Greer, P.A. Feline sarcoma-related protein expression correlates with malignant aggressiveness and poor prognosis in renal cell carcinoma. Cancer Sci. 2013, 104, 681-686. [CrossRef] [PubMed] 
30. Morris, C.; Heisterkamp, N.; Hao, Q.L.; Testa, J.R.; Groffen, J. The human tyrosine kinase gene (fer) maps to chromosome 5 and is deleted in myeloid leukemias with a del(5q). Cytogenet. Cell Genet. 1990, 53, 196-200. [CrossRef] [PubMed]

31. Ueno, K.; Kumagai, T.; Kijima, T.; Kishimoto, T.; Hosoe, S. Cloning and tissue expression of cdnas from chromosome 5q21-22 which is frequently deleted in advanced lung cancer. Hum. Genet. 1998, 102, $63-68$. [CrossRef] [PubMed]

32. MacKeigan, J.P.; Murphy, L.O.; Blenis, J. Sensitized rnai screen of human kinases and phosphatases identifies new regulators of apoptosis and chemoresistance. Nat. Cell Biol. 2005, 7, 591-600. [CrossRef] [PubMed]

33. Senis, Y.A.; Craig, A.W.; Greer, P.A. Fps / fes and fer protein-tyrosinekinases play redundant roles in regulating hematopoiesis. Exp. Hematol. 2003, 31, 673-681. [CrossRef]

34. Westerfield, M. The Zebrafish Book, 5th ed.; University of Oregon Press: Eugene, OR, USA, 2007.

35. Thisse, C.; Thisse, B. High-resolution in situ hybridization to whole-mount zebrafish embryos. Nat. Protoc. 2008, 3, 59-69. [CrossRef] [PubMed]

36. Covassin, L.; Amigo, J.D.; Suzuki, K.; Teplyuk, V.; Straubhaar, J.; Lawson, N.D. Global analysis of hematopoietic and vascular endothelial gene expression by tissue specific microarray profiling in zebrafish. Dev. Biol. 2006, 299, 551-562. [CrossRef] [PubMed]

37. Dunn, E.M.; Putzke, A.P. Whitworth University, Spokane, WA, USA. Unpublished Data. 2018.

38. Gross, L.A.; Baird, G.S.; Hoffman, R.C.; Baldridge, K.K.; Tsien, R.Y. The structure of the chromophore within dsred, a red fluorescent protein from coral. Proc. Natl. Acad. Sci. USA 2000, 97, 11990-11995. [CrossRef] [PubMed]

39. Matz, M.V.; Fradkov, A.F.; Labas, Y.A.; Savitsky, A.P.; Zaraisky, A.G.; Markelov, M.L.; Lukyanov, S.A. Fluorescent proteins from nonbioluminescent anthozoa species. Nat. Biotechnol. 1999, 17, 969-973. [CrossRef] [PubMed]

40. Lee, C.Y.; Vogeli, K.M.; Kim, S.H.; Chong, S.W.; Jiang, Y.J.; Stainier, D.Y.; Jin, S.W. Notch signaling functions as a cell-fate switch between the endothelial and hematopoietic lineages. Curr. Biol. 2009, 19, 1616-1622. [CrossRef] [PubMed]

41. Kalev-Zylinska, M.L.; Horsfield, J.A.; Flores, M.V.; Postlethwait, J.H.; Vitas, M.R.; Baas, A.M.; Crosier, P.S.; Crosier, K.E. Runx1 is required for zebrafish blood and vessel development and expression of a human runx1-cbf2t1 transgene advances a model for studies of leukemogenesis. Development 2002, 129, 2015-2030. [PubMed]

42. Lawson, N.D.; Scheer, N.; Pham, V.N.; Kim, C.H.; Chitnis, A.B.; Campos-Ortega, J.A.; Weinstein, B.M. Notch signaling is required for arterial-venous differentiation during embryonic vascular development. Development 2001, 128, 3675-3683. [PubMed]

43. Zhong, T.P.; Childs, S.; Leu, J.P.; Fishman, M.C. Gridlock signalling pathway fashions the first embryonic artery. Nature 2001, 414, 216-220. [CrossRef] [PubMed]

44. Burns, C.E.; Traver, D.; Mayhall, E.; Shepard, J.L.; Zon, L.I. Hematopoietic stem cell fate is established by the notch-runx pathway. Genes Dev. 2005, 19, 2331-2342. [CrossRef] [PubMed]

45. Siekmann, A.F.; Lawson, N.D. Notch signalling limits angiogenic cell behaviour in developing zebrafish arteries. Nature 2007, 445, 781-784. [CrossRef] [PubMed]

46. Bertrand, J.Y.; Cisson, J.L.; Stachura, D.L.; Traver, D. Notch signaling distinguishes 2 waves of definitive hematopoiesis in the zebrafish embryo. Blood 2010, 115, 2777-2783. [CrossRef] [PubMed]

47. Sangrar, W.; Gao, Y.; Bates, B.; Zirngibl, R.; Greer, P.A. Activated fps/fes tyrosine kinase regulates erythroid differentiation and survival. Exp. Hematol. 2004, 32, 935-945. [CrossRef] [PubMed]

48. Lam, E.Y.; Hall, C.J.; Crosier, P.S.; Crosier, K.E.; Flores, M.V. Live imaging of runx1 expression in the dorsal aorta tracks the emergence of blood progenitors from endothelial cells. Blood 2010, 116, 909-914. [CrossRef] [PubMed]

49. Huang, H.; Woo, A.J.; Waldon, Z.; Schindler, Y.; Moran, T.B.; Zhu, H.H.; Feng, G.S.; Steen, H.; Cantor, A.B. A src family kinase-shp2 axis controls runx1 activity in megakaryocyte and t-lymphocyte differentiation. Genes Dev. 2012, 26, 1587-1601. [CrossRef] [PubMed]

50. Cai, Z.; de Bruijn, M.; Ma, X.; Dortland, B.; Luteijn, T.; Downing, R.J.; Dzierzak, E. Haploinsufficiency of aml1 affects the temporal and spatial generation of hematopoietic stem cells in the mouse embryo. Immunity 2000, 13, 423-431. [CrossRef] 
51. Jacob, B.; Osato, M.; Yamashita, N.; Wang, C.Q.; Taniuchi, I.; Littman, D.R.; Asou, N.; Ito, Y. Stem cell exhaustion due to runx1 deficiency is prevented by evi5 activation in leukemogenesis. Blood 2010, 115, 1610-1620. [CrossRef] [PubMed]

52. Lee, J.; Kotov, N.A. Notch ligand presenting acellular $3 \mathrm{~d}$ microenvironments for ex vivo human hematopoietic stem-cell culture made by layer-by-layer assembly. Small 2009, 5, 1008-1013. [CrossRef] [PubMed]

53. Voisset, E.; Lopez, S.; Chaix, A.; Georges, C.; Hanssens, K.; Prebet, T.; Dubreuil, P.; De Sepulveda, P. Fes kinases are required for oncogenic flt3 signaling. Leukemia 2010, 24, 721-728. [CrossRef] [PubMed]

54. Mitchell, I.C.; Brown, T.S.; Terada, L.S.; Amatruda, J.F.; Nwariaku, F.E. Effect of vascular cadherin knockdown on zebrafish vasculature during development. PLOS ONE 2010, 5. [CrossRef] [PubMed]

55. Friedrich, E.B.; Liu, E.; Sinha, S.; Cook, S.; Milstone, D.S.; MacRae, C.A.; Mariotti, M.; Kuhlencordt, P.J.; Force, T.; Rosenzweig, A.; et al. Integrin-linked kinase regulates endothelial cell survival and vascular development. Mol. Cell. Biol. 2004, 24, 8134-8144. [CrossRef] [PubMed]

56. Sangrar, W.; Gao, Y.; Zirngibl, R.A.; Scott, M.L.; Greer, P.A. The fps/fes proto-oncogene regulates hematopoietic lineage output. Exp. Hematol. 2003, 31, 1259-1267. [CrossRef] [PubMed]

57. Arregui, C.; Pathre, P.; Lilien, J.; Balsamo, J. The nonreceptor tyrosine kinase fer mediates cross-talk between n-cadherin and beta1-integrins. J. Cell Biol. 2000, 149, 1263-1274. [CrossRef] [PubMed]

58. North, T.E.; Goessling, W.; Peeters, M.; Li, P.; Ceol, C.; Lord, A.M.; Weber, G.J.; Harris, J.; Cutting, C.C.; Huang, P.; et al. Hematopoietic stem cell development is dependent on blood flow. Cell 2009, 137, 736-748. [CrossRef] [PubMed]

59. Kim, A.D.; Melick, C.H.; Clements, W.K.; Stachura, D.L.; Distel, M.; Panakova, D.; MacRae, C.; Mork, L.A.; Crump, J.G.; Traver, D. Discrete notch signaling requirements in the specification of hematopoietic stem cells. EMBO J. 2014, 33, 2363-2373. [CrossRef] [PubMed]

60. Hellstrom, M.; Phng, L.K.; Gerhardt, H. Vegf and notch signaling: The yin and yang of angiogenic sprouting. Cell Adhes. Migr. 2007, 1, 133-136. [CrossRef]

61. Quillien, A.; Moore, J.C.; Shin, M.; Siekmann, A.F.; Smith, T.; Pan, L.; Moens, C.B.; Parsons, M.J.; Lawson, N.D. Distinct notch signaling outputs pattern the developing arterial system. Development 2014, 141, 1544-1552. [CrossRef] [PubMed]

62. Ivanova, I.A.; Vermeulen, J.F.; Ercan, C.; Houthuijzen, J.M.; Saig, F.A.; Vlug, E.J.; van der Wall, E.; van Diest, P.J.; Vooijs, M.; Derksen, P.W. Fer kinase promotes breast cancer metastasis by regulating alpha6and beta1-integrin-dependent cell adhesion and anoikis resistance. Oncogene 2013, 32, 5582-5592. [CrossRef] [PubMed] 